\title{
Electrical power generation through concentrated solar technology for the southern cities of Iraq
}

\author{
Riyadh Toman Thahab ${ }^{1}$, Ahmed Toman Thahab ${ }^{2}$ \\ ${ }^{1}$ Departement of Electrical Engineering, University of Babylon, Iraq \\ ${ }^{2}$ Departement of Biomedical Engineering, University of Babylon, Iraq
}

\begin{tabular}{l} 
Article Info \\
\hline Article history: \\
Received Sep 15, 2019 \\
Revised Nov 12, 2019 \\
Accepted Jan 11, 2020 \\
\hline
\end{tabular}

Keywords:

Concentrated solar power

Direct normal irradiance

Electrical energy

Hyberdized solar plant

Tilted collector

\begin{abstract}
With a continuing mismatch between generating capacity and demand requirements, Iraqi cities are still enduring scheduled power outages. In this work, concentrated solar power (CSP) technology is proposed and designed for Iraqi cities to inject power into distribution networks with the objective of boosting the generating power capacity. Since CSP systems require a preliminary study of the direct normal irradiance (DNI), analyses of monthly data is carried out for each of the candidate cities. This is followed by determination of the amount of solar irradiance that falls on a titled collector per month considering the effects of reflection and diffusion. Finally, a thermal power plant is proposed and simulated using the system advisory model (SAM) per city. Results presented show an encouraging number of metrics and confirm the feasibility of such a plant in southern Iraq. The levelised cost of electricity and capacity factor shows a considerable decrease and increase respectively, when the plant is backed up by a fossil fuel steam cycle under circumstances when a plant loses over $80 \%$ of the MW capacity due to drop in solar irradiance. To provide a comparision platform, for each city, a photovolitaic (PV) plant is designed with an indentical electric capacity to that of the CSP plant. Findings from this work confirm that CSP plants can provide a suitstanable and enviroemntl friendly solution to electrical power shortages in the country compared to the current PV trends.
\end{abstract}

Copyright $(2020$ Institute of Advanced Engineering and Science. All rights reserved.

\section{Corresponding Author:}

Riyadh Toman Thahab,

Departement of Electrical Engineering,

University of Babylon,

Alnajaf-Hillah Road, Hillah, Babylon Province, Iraq,

Email: riyadhtomanth.toman@wmich.edu

\section{INTRODUCTION}

Characterized as plentiful, solar energy has great potentials as far as electricity generation is concerned. Obtaining electric power from solar power depends on whether light or heat is captured. In photovoltaic systems (PV), sun light is converted to electricity via arrays. On the other hand CSP, which depends on heat, concentrate the solar light such that heat is transferred to a power block for steam production and eventually electricity generation. The Middle East region is identified as a potential location for CSP due to the ample solar irridance available [1]. Several countries have conducted assessment studies of CSP technology as source of electric power generation. Authors in [2] identified locations in Iran for a feasible CSP system. Based on the assessment study, six cities have weather features for a successful CSP plant. Authors presented a $100 \mathrm{MW}$ thermal plant design, with six hours of energy storage, for each of the six locations. In neighboring Jordan, authors in [3] present an optimized plant to be installed at Ma'an location. Authors in this work compare a $50 \mathrm{MW}$ plant with wet and dry cooling methods. The levelized cost of electricity (LCOE) is considered as the variable to be minimized in the optimization by changing thermal 
energy storage hours, solar multiples,cooling method and turbine size. Authors conclude that CSP has a prospective to boost the economy of Jordan as far as the energy sector is concerned. Work presented in [4] explored CSP implementation in Mediterranean weather conditions. The study assesses CSP in four areas of Algeria, where a $100 \mathrm{MW}$ plant is designed for each region. The authors conclude that despite the high cost of installing a CSP, however long term paybacks can benefit Algeria. Authors in [5] studied implementation of CSP in the area of Jubail in Saudi Arabia. Authors report that such a plant can provide $86.5 \mathrm{GWh}$ of electrical energy at an overall efficiency of 23.2\%. Study of CSP feasibility is presented for Tunis in [6], for Spain [7], for India [8] and for Eygpt in [9]. Authors in [10] presented a study of the effects of a CSP plant connection to Chilean power system with energy storage options. Without storage, the challenge of achieving a balance between load and generation powers is much more proununced [11]

Iraq is undergoing a shortage of electric power due to many reasons specially with the ever increasing load demand. Systematic shedding of loads is a permanent procedure that utility authorities adopt to achieve a power balance. In the meantime, Iraqi weather with a long hot summer can serve as a resource to alleviate the electricity shortages. Research, however,to the best of our knowledge, has been limited as far as a full extent study of thermal power plant is concerned. A more recent work in [12] explored the potentials of renewable energy in Iraq with a particular emphasis on solar based generation. Authors report that the country can benefit from a CSP in a stand-alone fashion or the plant can be used as a steam source to current thermal power stations. In general authors estimate that with zero thermal energy storage (TES), the cost of electricity is about 0.23 cents/KWh. Work in $[13,14]$ dealt mainly with the amount of global irradiance that falls horizontally on a surface for the city Baghdad. Authors in [15], presented solar radiation analysis for six Iraqi cities, where it's reported that maximum radiation occurs in the summer season and the minimum is attained in winter. However [13-15] provide mainly radiation anaylis and doesn't extend to a CSP plant study for electricity generation.

In this paper, a full extent analysis and design of a thermal power plant in four Iraqi cities are presented. The cities are located in southern Iraq, an area where temperatures cross $50 \mathrm{C}^{\circ}$ in summer times. An analysis is conducted to determine the amount of global horizontal and direct normal irradiance (GHI) and (DNI) for each city respectively. Then the amount of incident irradiance on a tilted collector is determined mathematically. The paper finally presents designs for a $100 \mathrm{MW}$ plant for two cities and $50 \mathrm{MW}$ for the other two locations of the Iraqi south.

\section{IRRADIANCE ANALYSIS AND OTHER SITE REQUIRMENTS}

A main requirement for a successful and economically feasible CSP based power plant is the amount of irradiance that is captured in a site. The irradiance amount used for planning purposes is the DNI and this amount should exceed, on average, $1800 \mathrm{KWh} / \mathrm{m}^{2}$-year for a cost worthy attractive project $[2,16]$. The four cities, located in south of the country, included in this study are Basra, Nasiriyah, Amarah and Samawah. Data of GHI and DNI have been downloaded for each city from European Commsions's Photovolitaic Geographical Information System (PVGIS) [17]. Figures 1 and 2 show the GHI and DNI profiles for the four cities per month. The mean annual GHI and DNI are calculated and shown in Table 1. Results for both GHI and DNI show,in general, a nearly similar profile for the locations with the city of Amarah having a peak DNI of about $350 \mathrm{~W} / \mathrm{m}^{2}$ during the month of June. Basra data show a peak DNI that is nearly constant from June to September. Samawah city has a peak irridance which starts in June and begins droping in subsequent months.

This city is located in the upper south, more close to the mid region of the country and hence it's affected by the mid-Euphrates regional weather, but, the mean annual DNI is $2938 \mathrm{KW} / \mathrm{m}^{2}$-year. The cities of Basra and Samawah have a DNI that stairs-up from January with Amarah showing a similar tendency. GHI and DNI for Nasiriyah, stairs up and down for the first five months of the year before peaking at June and climbing down for the rest of the year. Its worth mentioning that the monthly data collected from [17] were for the years 2007-2016 for each city in the country. Based on the results in this section it is clear that all cities have suitable irradiance potentials to be candidates for a CSP based power plant. Additional requirements for a CSP power plant are summarized as below:

a. The site where the CSP power plant is to be erected should be level, with a slope of 1-3\% [16] with $1 \%$ or less being the mostly desired [18]. This enables CSP collectors to avoid shadowing and other factors that may degrade the amount of captured irradiance

b. Wind speed at site should be less than $15.64 \mathrm{~m} / \mathrm{s}$ to avoid damage to the collectors [19].

c. The presence of a grid transmission such that on-grid connection is feasible [16].

Southern Iraq is characterized by its flat territory; in fact it represents part of the Sedimentary plain area of the country which fulfills the first requirement mentioned above. Figure 3 and 4 shows averaged monthly wind speeds and temperatures for the considered cities based on weather data from [17]. All cities 
have monthly wind speeds that fall well below the value specified in requirement 2 above. Temperature profiles are almost identical in all considered cities with peaks occurring during the month of July and August. As for requirement 3, Iraqi transmission network is scattered all around the country and hence this is not hurdle for a promising CSP power plant, Hence all four cities fulfill the essential requirements to a successful and economically rewarding CSP power plant.
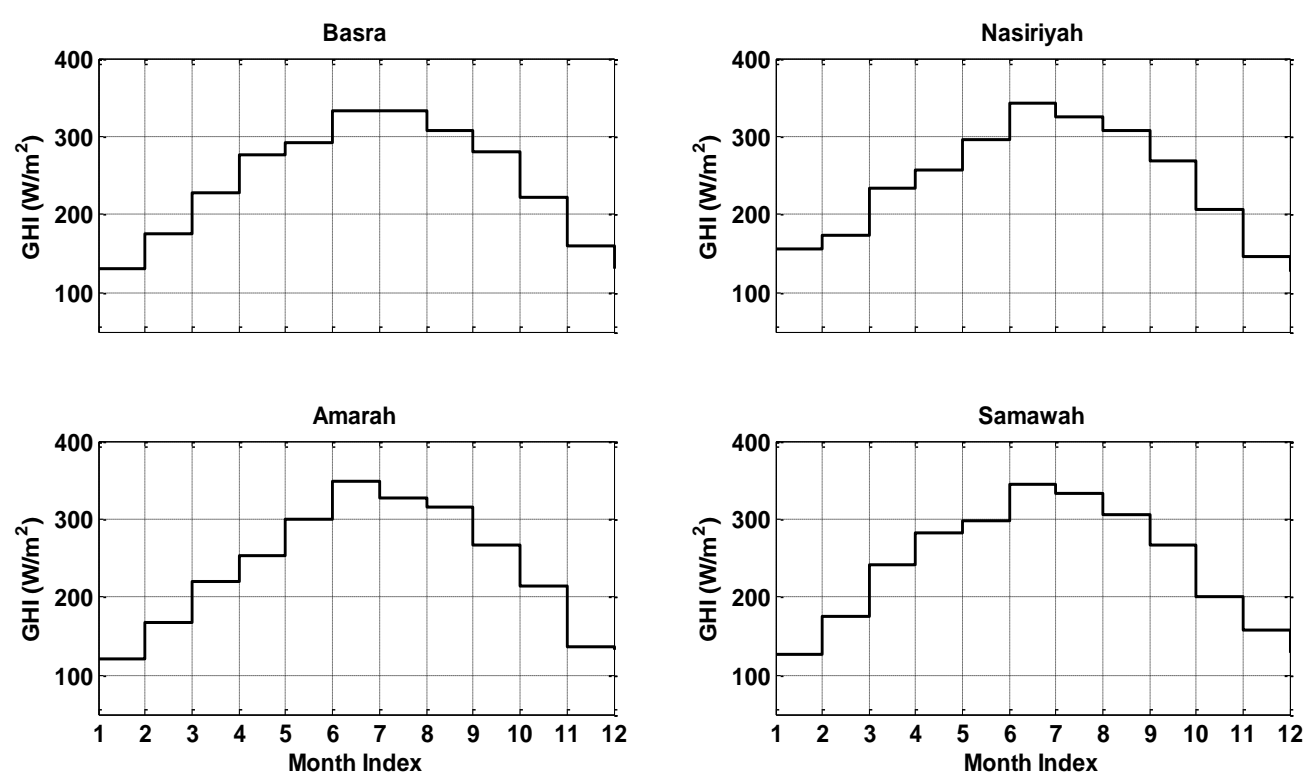

Figure 1. GHI profile for southern Iraqi cities
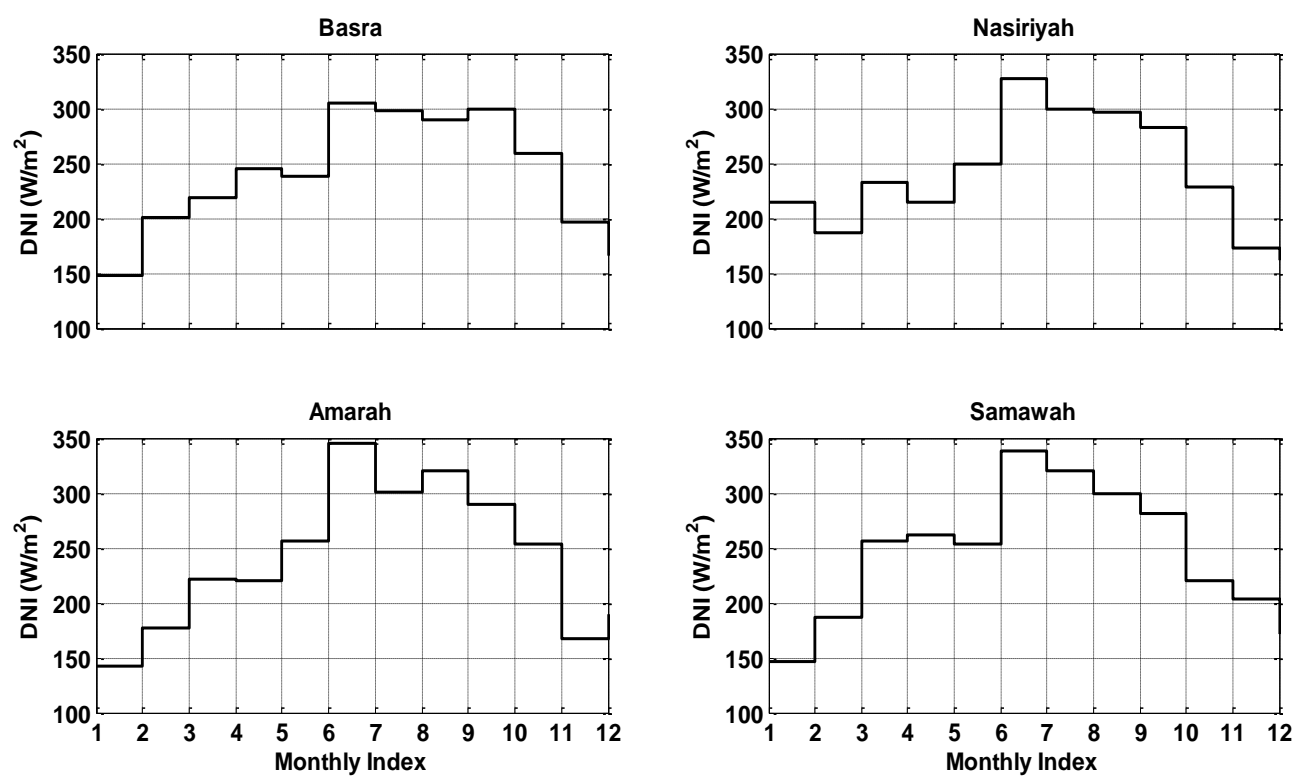

Figure 2. DNI profile for southern cities of Iraq

Table 1. Annual GHI for southern cities of Iraq

\begin{tabular}{ccc}
\hline City & GHI $(\mathrm{KW} / \mathrm{m} 2)$ & DNI $(\mathrm{KW} / \mathrm{m} 2)$ \\
\hline Basra & 2870 & 2864 \\
Nasiriyah & 2843 & 2866 \\
Amarah & 2801 & 2880 \\
Samawah & 2859 & 2938 \\
\hline
\end{tabular}



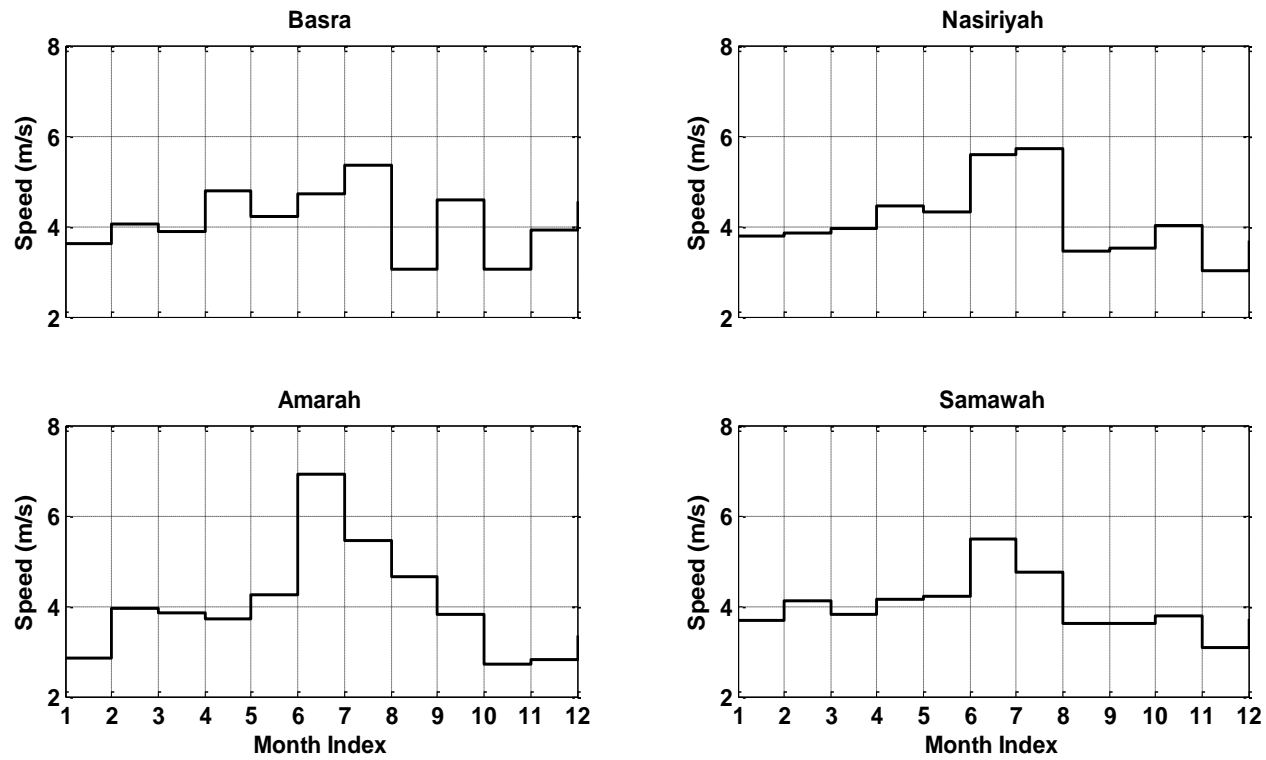

Figure 3 .Monthly wind speeds for Iraqi cities
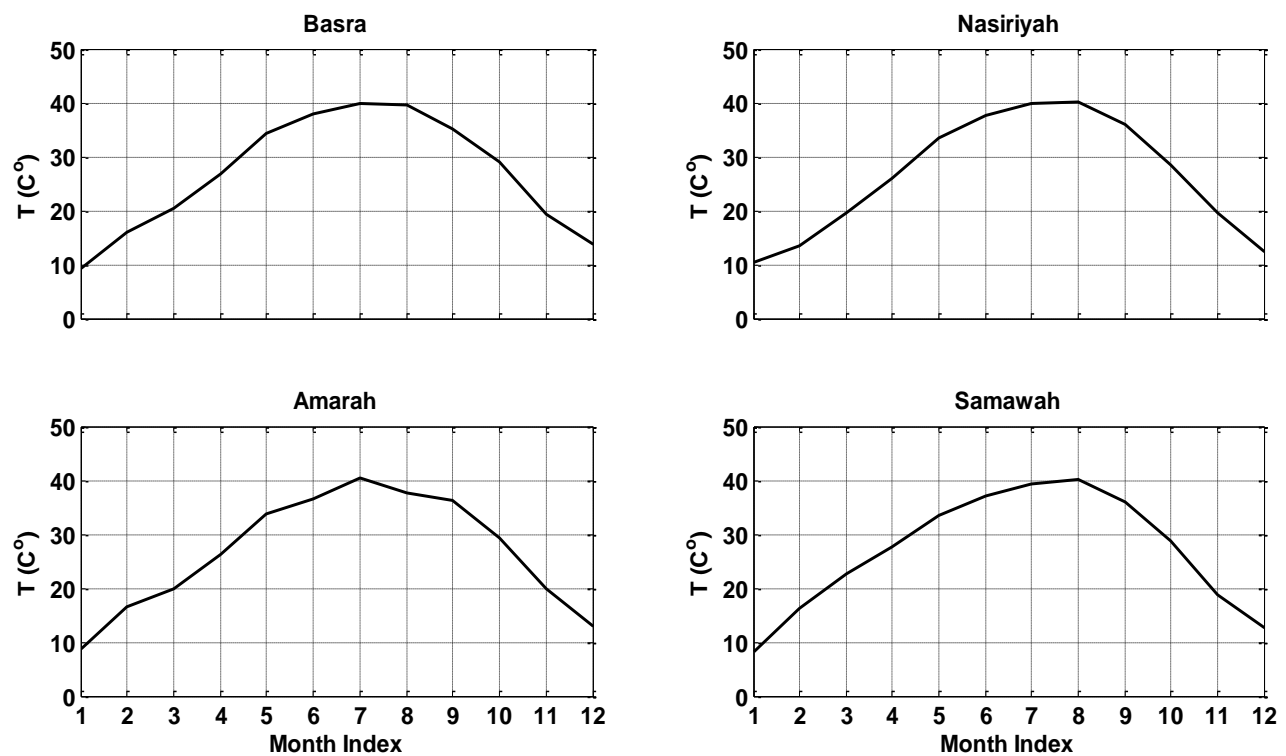

Figure 4.Temperatures for candidate Iraqi cities

\section{CALCULATION OF TOTAL IRRADIANCE ON A TILTED COLLECTOR}

It is a usual practice to place a collector of a concentrated solar field so that it makes an angle relative to the horizontal ground with the objective of increasing the reflected area [20]. This angle is called the tilt or slope angle [21]. The DNI captured by a tilted collector is less than that of a non-tilted [21]. Hence, in this section we first present a formula for total irradiance of a tilted collector, then this value is calculated for each of the considered Iraqi city. Since the total irradiance is a combination of the direct, reflected and diffusion components [22], individual components are calculated for each city. The declination and sunrise hour angle is given by [22]:

$$
\begin{aligned}
& \delta=23.45 \sin \left(\frac{360}{365}(n-81)\right) \\
& W_{S R}=\cos ^{-1}(-\tan L \tan \delta)
\end{aligned}
$$


where:

$\delta$ is the declination angle.

$\mathrm{n}$ is the order of the day.

$\mathrm{W}_{\mathrm{SR}}$ is the sunrise hour angle.

$\mathrm{L}$ is the latitude of city under study.

The daily mean extraterrestrial irradiance is given by [22]:

$$
\overline{E T I}=\left[\left(\frac{24}{\pi}\right) G\left(1+0.034 \cos \frac{360 n}{365}\right)\right]\left(\cos L \cos \delta \sin W_{S R}+W_{S R} \sin L \sin \delta\right)
$$

where $\mathrm{G}$ is the solar constant and is equal to $1.37 \mathrm{KW} / \mathrm{m} 2$ [22].

The average monthly irradiance $(\overline{G H I})$, which is measured when the collector is in a horizontal position, can be decomposed into two components, the average direct beam that fall on a horizontal collector and the average diffuse component, expressed mathematically as [22],

$$
\overline{G H I}=\overline{D N I}+\overline{D H I}
$$

where $\overline{\mathrm{DNI}}$ and $\overline{\mathrm{DHI}}$ are the average monthly direct normal and horizontal diffuse components respectively. The clearness index for each city considered in this study is defined as [22],

$$
K_{T}=\frac{\overline{G H I}}{\overline{E T I}}
$$

The ratio of the horizontal average diffuse to global irradiance is expressed in terms of the clearness index using the Liu and Jordan correlation equation as reported in [22],

$$
\overline{\overline{G H I}}=1.39-4.027 K_{T}+5.531 K_{T}^{2}-3.108 K_{T}^{3}
$$

It is known that the collector captures irradiance not only from the component that directly falls on the collector surface but also from that reflect by the ground in addition to the diffuse component. The reflected component is defined as [22],

$$
\overline{R H I}=\rho \overline{G H I}
$$

Where $\overline{\mathrm{RHI}}$ and $\rho$ are the reflected irradiance on a horizontal collector and the reflection index respectively. Hence, the total average irradiance falling on untitled collector is expressed as,

$$
\overline{I C_{T}}=\overline{D N I}+\overline{D H I}+\overline{R H I}
$$

where $\overline{\mathrm{IC}_{\mathrm{T}}}$ is the total average irradiance falling on an un-tilted collector. If a solar field collector is tilted by an $S^{o}$ with respect to the horizontal plane, then the direct normal, diffuse and reflection component are expressed as given in eq. 9, below [22],

$$
\begin{aligned}
& \overline{D N I}_{t}=\overline{R_{b}} \times \overline{D N I} \\
& \overline{D H I}_{t}=\overline{D H I} \times\left(\frac{1+\cos S}{2}\right) \\
& \overline{R H I}_{t}=\overline{R H I} \times\left(\frac{1-\cos S}{2}\right)
\end{aligned}
$$

where $\overline{\mathrm{DNI}}_{\mathrm{t}}, \overline{\mathrm{DHI}}_{\mathrm{t}}, \overline{\mathrm{RHI}}_{\mathrm{t}}$ and $\overline{R_{b}}$ are the direct, diffuse, reflected irradiances and average tilt factor respectively. The average tilt factor defined as the ratio of DNI of a tilted collector to that of an un-tilted and is given by [22],

$$
\overline{R_{b}}=\frac{\cos (L-S) \cos \delta \sin W_{S R C}+W_{S R C} \sin (L-\delta) \sin \delta}{\cos L \cos \delta \sin W_{S R}+W_{S R} \sin L \sin \delta}
$$

where $\mathrm{W}_{\mathrm{SRC}}$ is the sunrise hour angle of the collector as defined in [22]. Finally, the total irradiance falling on a tilted collector, $\overline{\mathrm{IC}_{\mathrm{Tt}}}$, is given by, 


$$
\overline{I C}_{T t}=\overline{D N I}_{t}+\overline{D H I}_{t}+\overline{R H I}_{t}
$$

Based on the above equations, $\overline{\mathrm{IC}_{\mathrm{Tt}}}$ is calculated for each city. The solar field collector is assumed to be tilted at $20^{\circ}$. Figure 5 depicts $\overline{\mathrm{IC}_{\mathrm{Tt}}}$ for each location which is found by adding up individual components per month. Cities like Nasiriya and Amarah show a continuous increase with total irradiance hitting the collector peaks at July and August. Basra shows a dip in irradiance during June, however recoded temperatures during this month may exceed $45^{\circ} \mathrm{C}$, and this may compensate the heat lost by the dip in the solar irradiance.
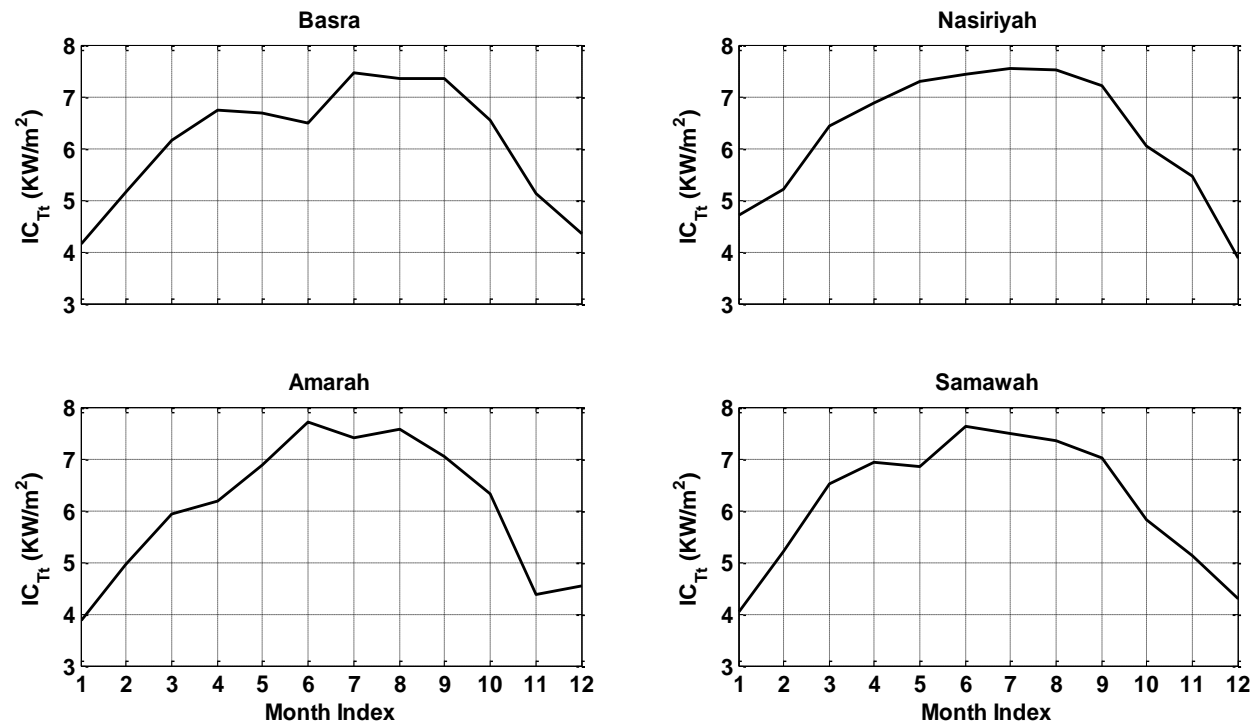

Figure 5. Total average irradiance hitting a $20^{\circ}$ tilted solar collector for each considered city

\section{SIMULATION OF A PARABOLIC TROUGH CSP PLANT FOR SOUTHERN IRAOI CITIES}

The plant simulated in this part is composed from a solar field of the parabolic trough type with thermal energy storage of 9 hours capacity. It is reported that parabolic trough based plants are widely available around the world due to the reliable operation that current plants has shown [20] and this encourages incoming users, like Iraq, to adopt such a technology. Simulation of the plant for each city is performed using the System Advisory Model (SAM) software developed by the National Renewable Energy Lab (NREL) [23] based on the weather data obtained from [17]. Figure 6 shows a block diagram of the approach design adopted in this work. Our emphasis is to optimize the design by maximizing the annual capacity factor and minimizing the leveled cost of electricity (LCOE). The capacity factor is a measure of how-much power the plant generates realative to the rated design power capacity over a lengthy period of time [20].

The electric capacity,at design, of the plant is 100 MW for Basra and Nasiriyah, whereas for Amarah and Samawah the capacity is $50 \mathrm{MW}$. These capacities are selected based on the area of each city. The gross to net output electrical power is designed to be 0.9 [23]. The main technical features of the CSP plant is summarized in Table 2. The design results is based on the irradiance analysis presented in previous section. The physical model in the SAM software is selected with the financial model that assumes a single owner (in Iraq this may represent the ministry of electricity) with a power purchase agreement. This is based on the assumption that the plant is tied to the utility grid. The system costs data which was entered to SAM is shown in Table 3. Some modifications have been added to account for the situation in Iraq which results in an LCOE estimation that reflects the finicial aspects of the country. In this work, the following assumptions has been adopted,

- The land used to erect the CSP plant is assumed to be state owned and hence its zero cost.

- No taxes are endured, since the owner is typically the ministry of Electricity.

- If the plant is backed up by fossil fuel [20], this fuel is free of charge (Iraq is an oil producing country).

The thermal energy storage is dispatched such that at any period of time in day, energy is released whenever solar power is not present. In this study, we will examine the effect of adding some fossil-fuel capacity on the capacity factor and LCOE for each city. 


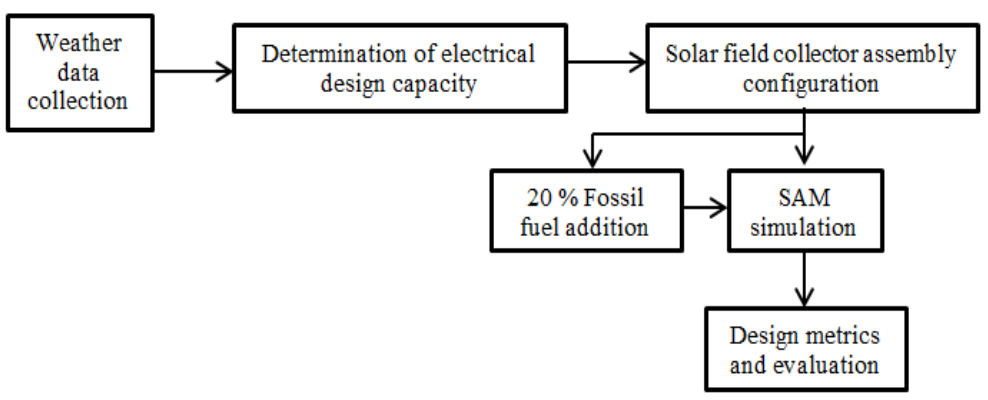

Figure. 6 Block diagram of CSP design for each city

Table 2. Main design specification of plant for each city

\begin{tabular}{|c|c|c|c|c|}
\hline Description & Basra & Nasiriyah & Amarah & Samawah \\
\hline Solar multiple & 2 & 2 & 2 & 2 \\
\hline Design MW & 100 & 100 & 50 & 50 \\
\hline Gross/net ratio & \multicolumn{4}{|c|}{0.9} \\
\hline Collector type & \multicolumn{4}{|c|}{ SkyFuel /SkyTrough (with 80-mm OD receiver) } \\
\hline Receiver type & \multicolumn{4}{|c|}{ Schott PTR80 } \\
\hline Heat transfer fluid & \multicolumn{4}{|c|}{ VP1 [4] } \\
\hline Thermal energy storage & \multicolumn{4}{|c|}{$9 \mathrm{hr}$} \\
\hline Storage heat transfer fluid & \multirow{2}{*}{\multicolumn{4}{|c|}{$\begin{array}{l}\text { Hitec Solar salt [4] } \\
0.1 \% \text { per vear in terms of annual energy production }\end{array}$}} \\
\hline Degradation rate & & & & \\
\hline
\end{tabular}

Table 3. System costs for CSP plant per city

\begin{tabular}{|c|c|c|c|}
\hline System cost & Basra & Nasiriyah & Samawah \\
\hline Site improvements & & $\$ 30 / \mathrm{m}^{2}[3]$ & \\
\hline Solar field & & $\$ 150 / \mathrm{m}^{2}[3]$ & \\
\hline Heat transfer fluid system & & $\$ 70 / \mathrm{m}^{2}[3]$ & \\
\hline Energy storage system & & $\$ 72 /$ KWht [3] & \\
\hline Fossil fuel & & 0 & \\
\hline Power plant (Power block) & & $\$ 940 /$ KWe [3] & \\
\hline Balance of plant & & $\$ 100 /$ KWe [3] & \\
\hline Land cost & & 0 & \\
\hline Fixed cost (operation and maintenance) & & $\$ 60 / \mathrm{KWe} /$ year [3] & \\
\hline
\end{tabular}

A thermal power plant is simulated for each city with and without fossil fuel support. One of the main superiority of a CSP technology, over other solar based electricity generation, is the ability to mix the operation between solar and fossil fuel in order to increase generation periods [20,24]. This can be done by a assigning a fossil fuel fraction, ranging from 0 to 1 in SAM [25]. Here a 0 denotes no fossil fuel contribution to the heat cycle, whereas a 1 means that fossil fuel will back up the steam generation process so as to obtain the installed MW capacity of the plant [25]. In this work, two cases of design are considered. The first assumes no fossil fuel back and the second considers a fossil fuel percentage of $20 \%$, which means if solar and thermal storage falls to a value such that the corresponding generated electrical power falls below $20 \%$ of the designed capacity, fossil fuel cycle is activated.

Figure 7 shows the gross electrical power output, in MWh, from the CSP plant for each considered city considering a zero and $20 \%$ fossil fuel fraction. Results show that the output electrical power reflects the irradiance status for each city per month. As solar irradiance increases, the amount of power generated undergoes a rise. Adding a fossil fuel fraction of $20 \%$, results in a very considerable increase in the gross output electric power. Practically the fossil fuel back up can further increase, especially in months where solar based heat is at its minimum. Figure 8 depicts the thermal power produced by the field and the input to the power block, $\mathrm{P}_{\text {Field }}$ and $\mathrm{P}_{\text {block }}$ measured in MWh for the case of zero fossil fuel fraction. With a $20 \%$ fraction $\mathrm{P}_{\text {Field }}$ and $\mathrm{P}_{\text {block }}$ profile is shown in Figure. 9.

To analyze the effect of a hybridized CSP plant, the difference between $\mathrm{P}_{\text {block }}$ and $\mathrm{P}_{\text {field }}$ for each month is also shown in Figure. 9. In this case the input power to the block is considerably higher than that produced by the field due the fossil fuel addition, which results in an improved capacity factor and lower LCOE. The supply of fuel in the southern part of Iraq is not a hurdle since a number of refineries exist in the area. Hence a hybrid plant works well in terms of providing ample thermal power to the generator block 
and can even offset the effect of non-sunshine hours and/ or cloudy days. However, for a zero fraction, the difference between $\mathrm{P}_{\text {block }}$ and $\mathrm{P}_{\text {field }}$ is always negative as expected since no support from fossil fuel is provided. The incident thermal power in the solar field per month in MWh is shown in Figure. 10 per city. This value is used to calculate the overall efficiency of the plant, which reflects the power flow and losses all the way from solar to electricity. Results from Figure. 10 shows that the city of Nasiriyah has the highest total solar power that is incident on the field, this is mainly due to the surplus solar irradiance the city has during all months of the year.
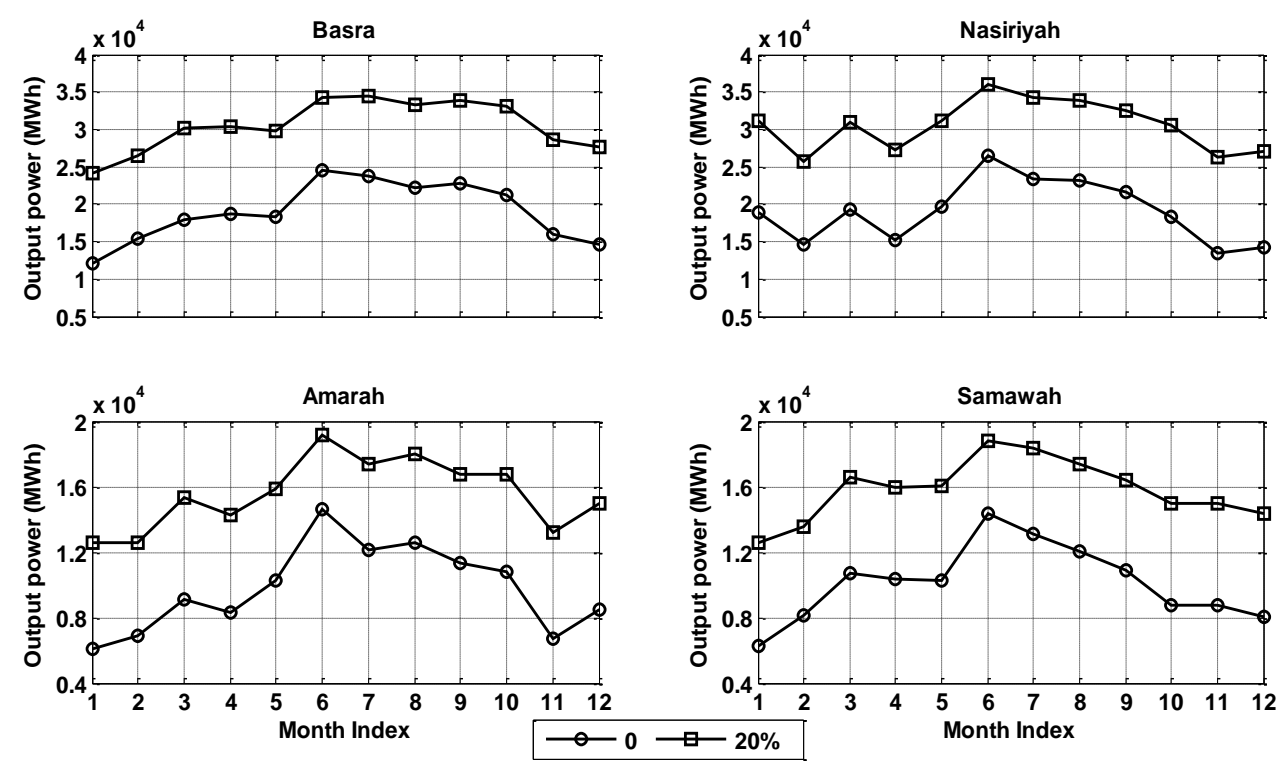

Figure 7. Output electrical generated from a CSP power plant for southern iraqi cities
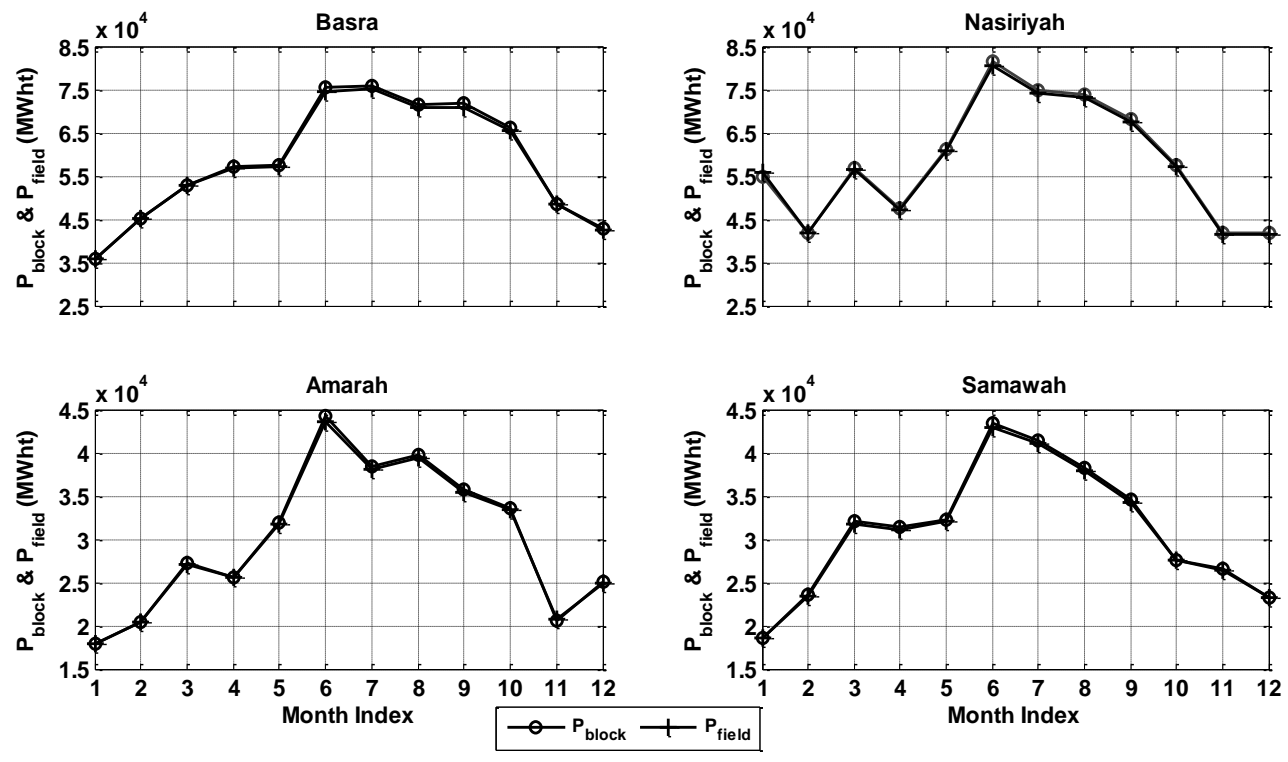

Figure 8 . Thermal power produced by the field and input to power block for zero fossil fuel fraction

The efficiency profile for the each CSP plant per city is shown in Figure. 11. Here, the efficiency in this case is the overall efficiency. Two cases are considered again, that is with and without fossil fuel back up. A considerable increase in the overall is evident. For the case zero fossil fuel case, the efficiency is nearly constant. For the $20 \%$ fossil fuel back up, in months from May to late August, the overall efficiency 
decreases, this is because the fraction adopted in this work is 0.2 which means that fossil fuel support will be activated if the solar based thermal power results in a decrease in the MW electrical output by $80 \%$. In these months solar irradiance is plentiful and hence the times during a day where fossil fuel support is activated is less compared to month days where solar irradiance is low. On the other hand, largely increasing the fossil fuel fraction may violate environmental protocols which renewable energy sources were meant to promote. Table 4 summarizes the results for each CSP plant per city. It is interesting to note that the LCOE is decreased considerably when the plant is hybridized with fossil fuel. In the city of Basra, LCOE decreases.
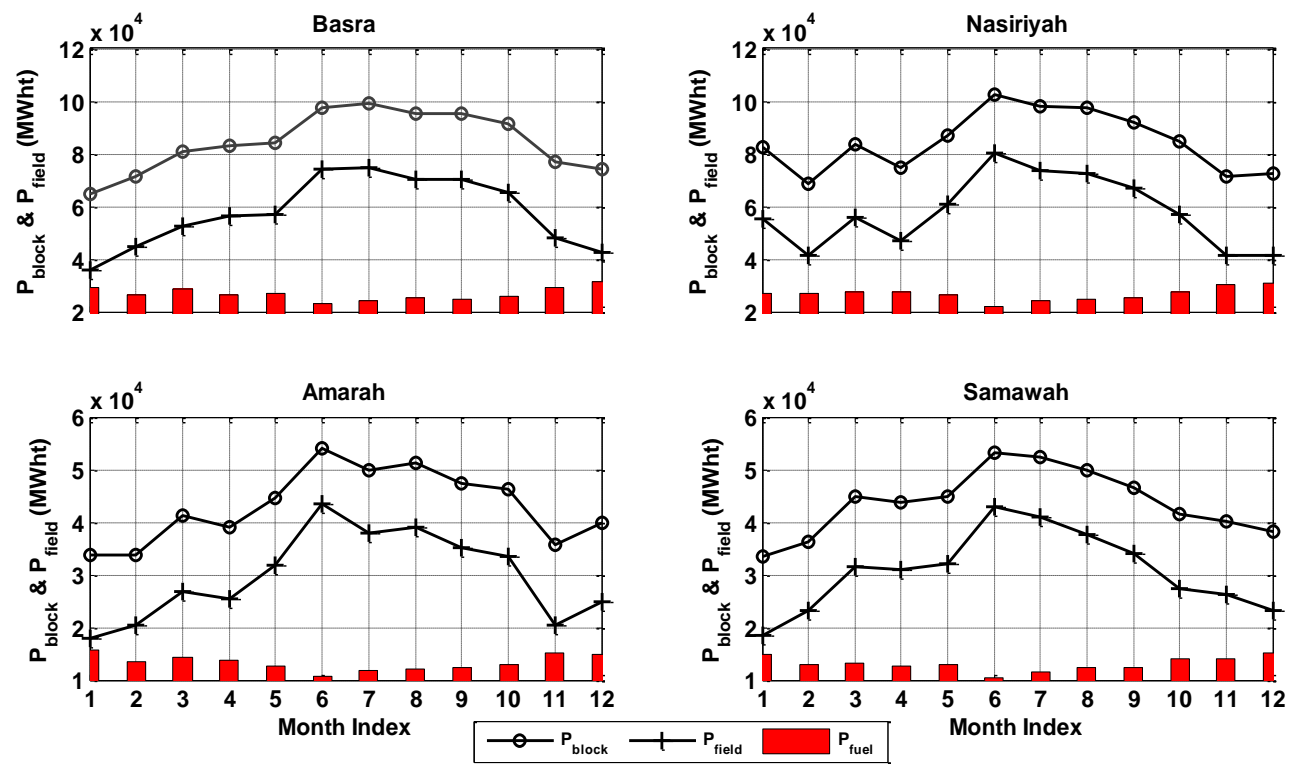

Figure 9. Thermal input to the power block, produced power by solar field and power contribution by fossil fuel at $20 \%$ fraction
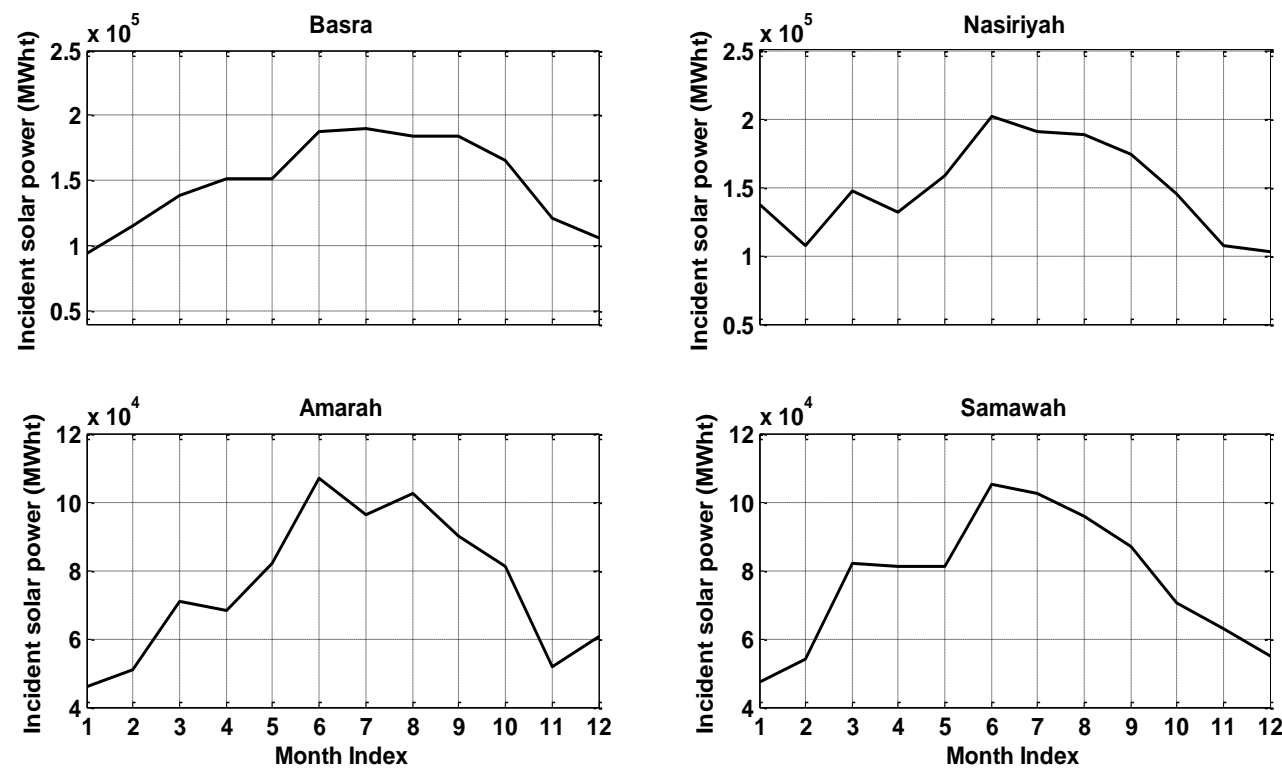

Figure 10. Total incident solar thermal power for each city

From 11.35 to $7.34 \phi / \mathrm{KWh}$. In addition, the plant capacity factor increases from $24.6 \%$ to $38.8 \%$, meaning that with zero fossil fuel, energy power is injected into the grid is $193.732944 \mathrm{GWh}$, whereas the with $20 \%$ fraction of fossil fuel, the plant supplies $305.675424 \mathrm{GWh}$ a year. All other cities considered in 
this study exhibits similar behavior, which implies that the southern Iraq area has significant potentials for a successful plant operation. At present, a number of thermal power plants are in service, if these plants can be complemented by a solar field as suggested in [12] the LCOE may go down considerably since the cost of the power block is eliminated. The annual water usage is also shown in Table 4, those quantities shouldn't be a major hurdle considering Iraq's two rivers are within the vicinity of the cities considered in this study.
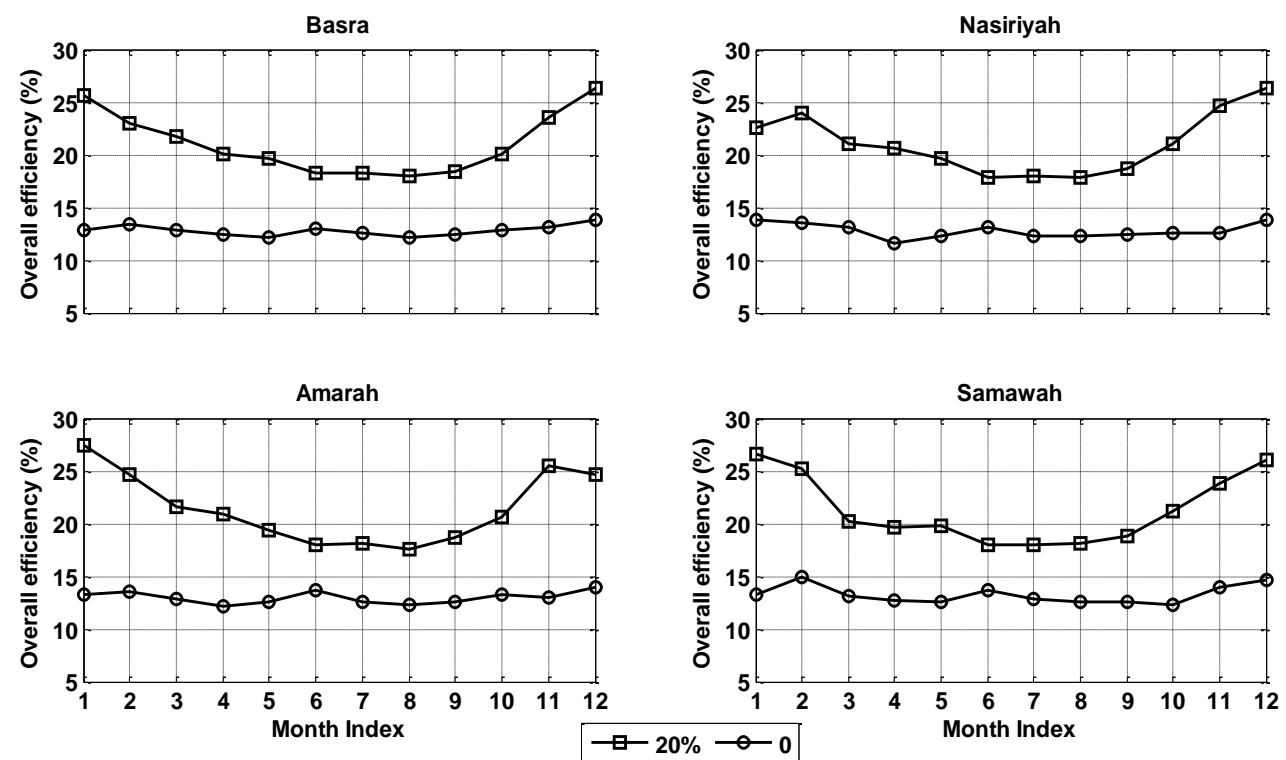

Figure 11. Overall efficiency of CSP plant for each city

Table 4. Results summary for CSP plant per city

\begin{tabular}{|c|c|c|c|c|c|c|c|c|}
\hline Description & \multicolumn{2}{|c|}{ Basra } & \multicolumn{2}{|c|}{ Nasiriyah } & \multicolumn{2}{|c|}{ Amarah } & \multicolumn{2}{|c|}{ Samawah } \\
\hline Fossil fuel fraction & 0 & $20 \%$ & 0 & $20 \%$ & 0 & $20 \%$ & 0 & $20 \%$ \\
\hline $\begin{array}{l}\text { Annual energy (first } \\
\text { year with no } \\
\text { degradation) (KWh) }\end{array}$ & $\begin{array}{c}193,732 \\
944\end{array}$ & $\begin{array}{l}305,675 \\
\quad 424\end{array}$ & $\begin{array}{c}194,762 \\
160\end{array}$ & $\begin{array}{l}307,052 \\
096\end{array}$ & $\begin{array}{c}98,319 \\
048\end{array}$ & $\begin{array}{l}154,748, \\
752\end{array}$ & $\begin{array}{c}102,274 \\
024\end{array}$ & $157,820,832$ \\
\hline Annual capacity factor & $24.6 \%$ & $38.8 \%$ & $24.7 \%$ & $38.9 \%$ & $24.9 \%$ & $39.3 \%$ & $25.9 \%$ & $40.0 \%$ \\
\hline $\begin{array}{l}\text { Gross/net electric } \\
\text { efficiency }\end{array}$ & $88.6 \%$ & $87 \%$ & $88.7 \%$ & $87.2 \%$ & $87.3 \%$ & $86.3 \%$ & $87.6 \%$ & $86.5 \%$ \\
\hline $\begin{array}{l}\text { Annual average overall } \\
\text { efficiency }\end{array}$ & $12.72 \%$ & $20.45 \%$ & $13.79 \%$ & $22.62 \%$ & $12.93 \%$ & $20.61 \%$ & $13.15 \%$ & $20.56 \%$ \\
\hline LCOE $(ф / K W h)$ & 11.35 & 7.34 & 11.30 & 7.31 & 11.22 & 7.27 & 10.80 & 7.14 \\
\hline $\begin{array}{l}\text { Annual water usage } \\
\qquad\left(\mathrm{m}^{3)}\right.\end{array}$ & 62,044 & 69,167 & 62,054 & 73,073 & 31,484 & 36,979 & 31,921 & 37,278 \\
\hline Net cost of CSP & \multicolumn{4}{|c|}{$\$ 465,556,576$} & \multicolumn{4}{|c|}{$\$ 233,473,648$} \\
\hline $\begin{array}{l}\text { Number of loops of } \\
\text { solar collectors }\end{array}$ & \multicolumn{4}{|c|}{163} & \multicolumn{4}{|c|}{82} \\
\hline $\begin{array}{l}\text { Required land area for } \\
\text { solar field }\left(\mathrm{Km}^{2}\right)\end{array}$ & \multicolumn{4}{|c|}{2.13674} & \multicolumn{4}{|c|}{1.07646} \\
\hline $\begin{array}{l}\text { Required land area for } \\
\text { total plant }\left(\mathrm{Km}^{2}\right)\end{array}$ & \multicolumn{4}{|c|}{2.99467} & \multicolumn{4}{|c|}{1.50543} \\
\hline
\end{tabular}

\section{COMPARISON OF ELECTRIC POWER GENERATION FOR PARABOLIC TROUGH CSP PERFORMANCE WITH PHOTOVOLTAIC SYSTEM}

In this section, a comparison is presented between CSP plant performances with a PV system for each city. The PV system is designed, using SAM [23], with an electric power capacity identical to that of the CSP plant. A grid tied PV system requires battery storage, a battery capacity is selected such that it matches the fossil fuel percentage adopted in this paper so as to provide an objective comparison. Designed PV system in this section is also based on weather data from [17] for each city. The amount of energy 
harvested from a PV system is considerably low compared to CSP as depicted in Figure 12 on a per month bases. This surplus in energy can provide a long term solution to Iraq's continuous energy shortages. Although the PV and CSP plants are identical in design capacity, yet the difference in energy production is clearly evident.
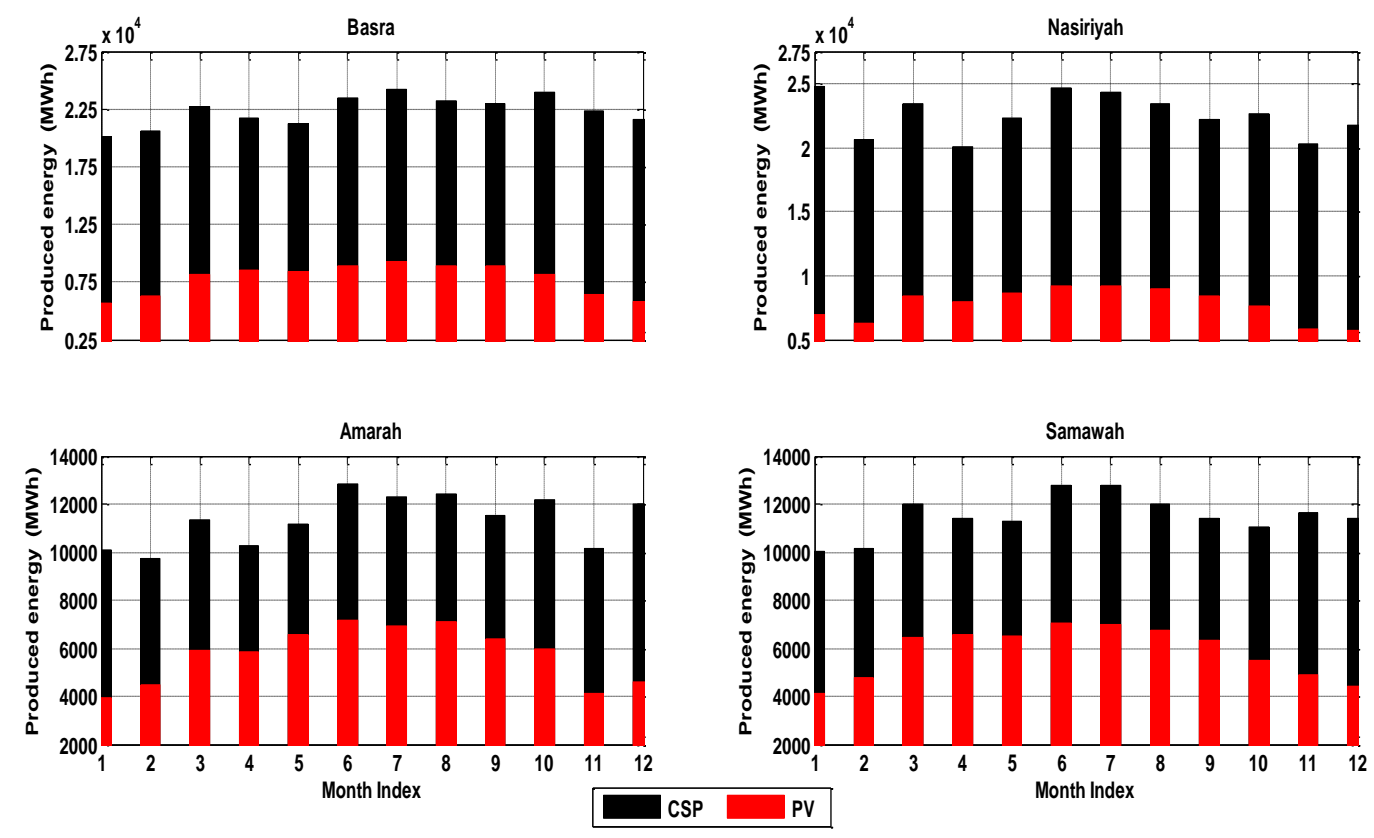

Figure 12. Monthly energy production for CSP and PV per city

Figure 13 shows the capacity factor of both solar technologies when the CSP plant has zero fossil fuel backup. Results verify that even with no backup, a CSP plant shows a higher capacity factor compared to a battery backup PV system. This capacity factor is significantly enhanced as the CSP is hybridized with a $20 \%$ fossil fuel plant as shown in Figure 14. This leads to the conclusion that a CSP plant hybridized by fossil fuel available in the country represents a far better solution compared to currently adopted PV systems. As far as the LCOE for the two system, the CSP system with only $20 \%$ fossil fuel operation is cheaper than the PV technology. Table 5 provides a comparison between a PV and CSP systems for each city in terms of LCOE and overall efficiency. Both solar technologies show a nearly similar conversion efficiency as far as total electrical energy produced relative to the thermal energy falling on PV panel or CSP collector.

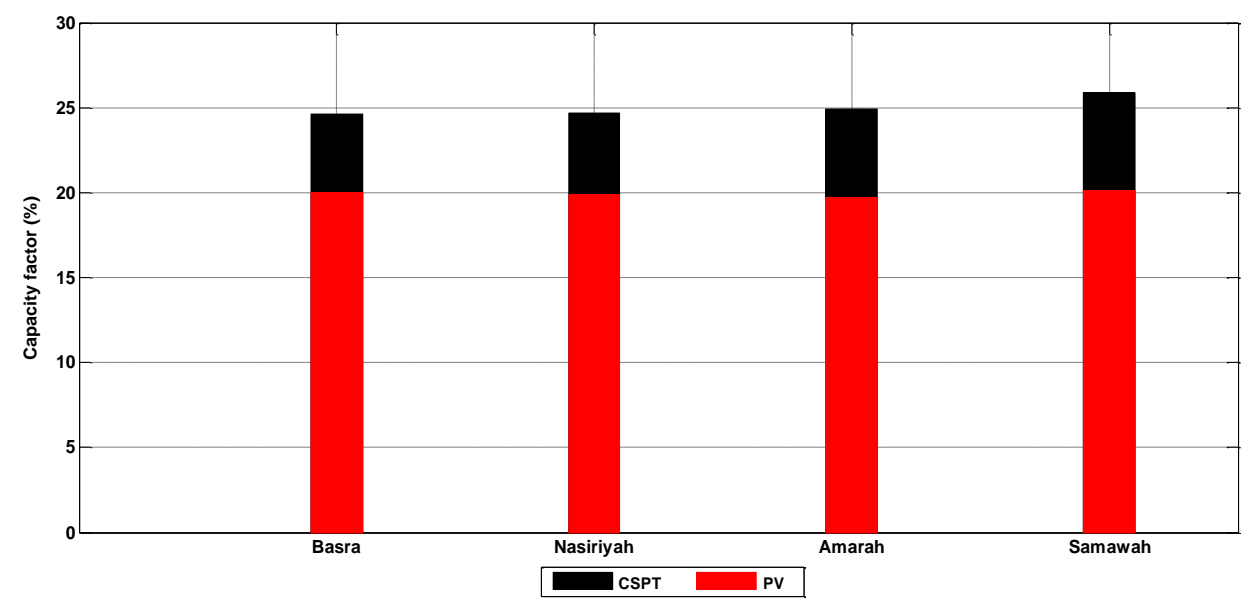

Figure 13. Capacity factor for PV and CSP generation with zero fossil fuel backup 


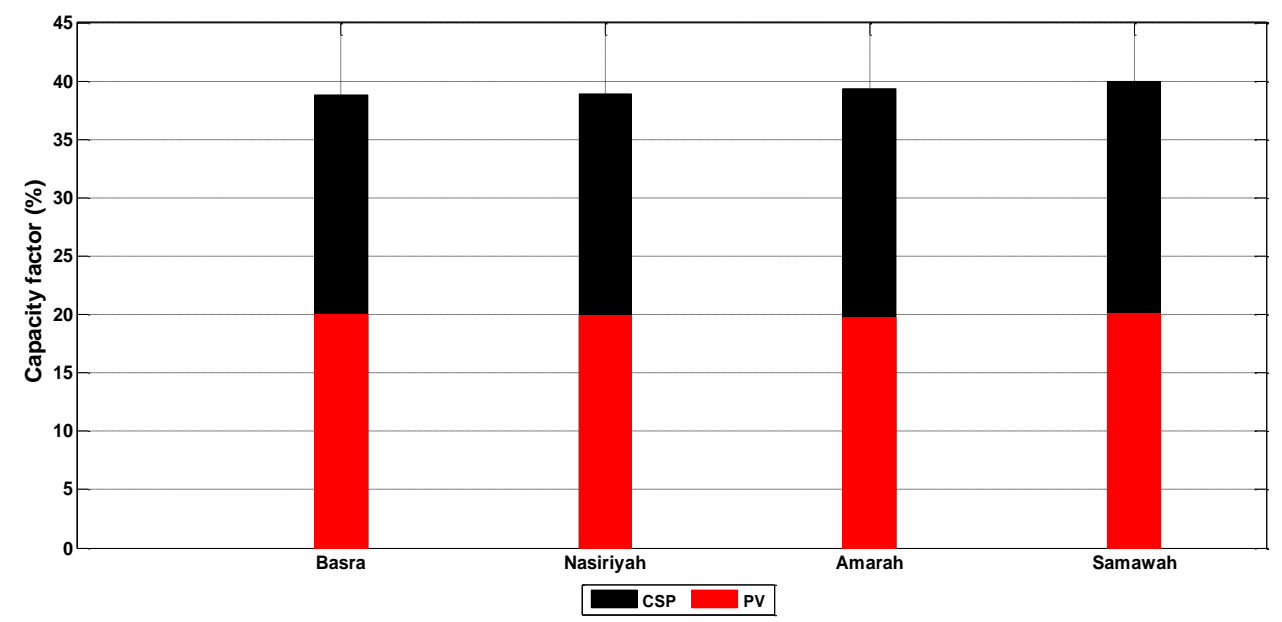

Figure 14. Capacity factor for PV and CSP generation for $20 \%$ fossil fuel backup

Table 5. Results summary for PV based electric generation per city

\begin{tabular}{ccccccccc}
\hline Description & \multicolumn{2}{c}{ Basra } & \multicolumn{2}{c}{ Nasiriyah } & \multicolumn{2}{c}{ Amarah } & \multicolumn{2}{c}{ Samawah } \\
\hline Solar technology & PV & $\begin{array}{c}\text { CSP with } \\
20 \% \mathrm{FF}\end{array}$ & PV & $\begin{array}{c}\text { CSP with } \\
20 \% \mathrm{FF}\end{array}$ & PV & CSP with & PV & CSP with \\
Annual average & & & & & $20 \% \mathrm{FF}$ & PF \\
overall efficiency & $15.84 \%$ & $20.45 \%$ & $15.86 \%$ & $22.62 \%$ & $15.92 \%$ & $20.61 \%$ & $15.91 \%$ & $20.56 \%$ \\
LCOE $(\phi / \mathrm{KWh})$ & 8.56 & 7.34 & 8.58 & 7.31 & 9.12 & 9.12 & 8.95 & 7.14 \\
\hline
\end{tabular}

\section{CONCLUSION}

A detailed analysis for a CSP power plant is presented for major cities located in southern Iraq. Data obtained reveals that irradiance which falls normally on flat surface, on an annual bases, exceeds the minimum value required to establish a solar field. Calculation of total average monthly irradiance which falls on a solar collector proves that ample solar ray is present in every city which further support the fact that a CSP power plant is feasible and economically justifiable in the southern region of Iraq. Four plants are designed for each city, with two different values of installed capacity. Results verify that with no fossil fuel back-up, a CSP plant has encouraging operating metrics such as capacity factors and levelized cost of electricity. These performance metrics are considerably improved when fossil fuel takes over at conditions where electrical output power drops below $20 \%$ of installation capacity due to lack of solar based power. Results obtained in this work are compared with a PV based generation designed for each city. The comparision verifies that CSP based generation proves itself as a very suitable source for grid tied operation and outweighs PVs which Iraq is currently using by far due to the high energy production and high capacity factor. Hence a CSP power plant with grid tied operation may play a dominant role in alleviating Iraq's continuous electrical energy shortages.

\section{REFERENCES}

[1] "The Middle East and North Africa Concentrated Solar Power Knowledge and Innovation Program," The World Bank and Clean Technology Fund, http://pubdocs.worldbank.org/en/608591486394607927/MENA-CSPKnowledge-and-Innovation-Program-EN.pdf. Accessed on $4^{\text {th }}$ September 2019.

[2] M. Enjavi - Arsanjania, Kamran Hirbodi, \& M. Yaghoubi, "Solar Energy Potential and Performance Assessment of CSP Plants in Different Areas of Iran," International Conference on Concentrating Solar Power and Chemical Energy Systems,solarPACES 2014, Energy Procedia, 69, ELSEVIER, vol. 69, pp. 2039-2048, 2015.

[3] Khaled M. Bataineh \& Ahmad Gharaibeh, "Optimization Analyses of Parabolic Trough (CSP) Plants for the Desert Regions of the Middle East and North Africa (MENA)," Jordan Journal of Mechanical and Industrial Engineering, vol. 12, no. 1, pp. 33-43, 2018.

[4] Mohamed Abbas, Zoubir Belgroun, Hanane Aburidah, \& Nachida Kasbadji Merzouk, "Assessment of a solar parabolic trough power plant for electricity generation under Mediterranean and arid climate conditions in Algeria," Mediterranean Green Energy Forum, Energy Procedia, 42, ELSEVIER, vol. 42, pp. 93-102, 2013.

[5] A. M. Al-Nasser, "Performance and economics of a solar thermal power generation plant in Jubail, Saudi Arabia: Parabolic trough collector," IEEE International Energy Conference, Manama, pp. 752-757, 2010. 
[6] Moncef Balghouthi, Seif Eddine Trabelsi, Mahmoud Ben Amara, Abdessalem Bel Hadj Ali \& Amenallah Guizani, "Potential of concentrating solar power (CSP) technology in Tunisia and the possibility of interconnection with Europe," Renewable and Sustainable Energy Reviews, Elsevier, vol. 56, pp. 1227-1248, 2016.

[7] G. San Miguel, B. Corona, "Economic viability of concentrated solar power under different regulatory frameworks in Spain," Renewable and Sustainable Energy Reviews Elsevier, vol. 91, pp. 205-218, 2018.

[8] Jay Prakash Bijarniya, K.Sudhakar and Prashant Baredar, "Concentrated solar power technology in India: A review," Renewable and Sustainable Energy Reviews, Elsevier, vol. 63, pp. 593-603, 2016.

[9] S. Elshafey et al., "Solar Thermal Power in Egypt," 2018 IEEE Industry Applications Society Annual Meeting (IAS), Portland, OR, pp. 1-8, 2018

[10] R. Mena, R. Escobar, Á. Lorca, M. Negrete-Pincetic, D. Olivares, "The impact of concentrated solar power in electric power systems: A Chilean case study," Applied Energy, Elsevier, vol. 235, pp. 258-283, 2019.

[11] Anil Kumar, Om Prakash \& Akarshi Dube, "A review on technology and promotional initiatives for concentrated solar power in world," International Journal of Ambient Energy, vol. 39,no. 3, pp.297-316, 2018.

[12] Al-Kayiem, Hussain \& Mohammad, Sanan, "Potential of Renewable Energy Resources with an Emphasis on Solar Power in Iraq: An Outlook," Resources MDPI, vol. 8, no. 42, pp. 1-20, 2019.

[13] Ahmed A. Al-Kayssi, Omar A. Abdulrazzaq, \& Nuha T. Hamad, "Analyzing of Global Solar Radiation over Baghdad," International Journal of Science and Research (IJSR), vol. 7, no. 9, pp. $306-308,2018$.

[14] Moafaq Al-Ghezi, "The Global and Scattered Radiation Evaluation for a Horizontal Surface in Baghdad City," International Journal of Computation and Applied Sciences, IJOCAAS, vol. 3, no. 1, pp. 153-158, 2017.

[15] Fadhil Abdulrazzaq Kareem, Noor Samir Lafta, \& Doaa Zaid Khalaf, "Energy and Exergy Analysis of the Solar Radiation Incident over Iraq," 2nd International Conference on Sustainable Engineering Techniques (ICSET 2019), IOP Conf. Series: Materials Science and Engineering, vol. 518, pp. 1-12, 2019.

[16] Qu Hang, Zhao Jun, Yu Xiao \& Cui Junkui, "Prospect of concentrating solar power in China - the sustainable future," Renewable and sustainable energy reviews, Science Direct, Elsevier, vol. 12, no. 9, pp. 2505-2514, 2008.

[17] European Commsions's Photovolitaic Geographical Information System (PVGIS), [Online]. Available: https://re.jrc.ec.europa.eu/pvg_tools/en/tools.html\#TMY. Accessed on $4^{\text {th }}$ September 2019.

[18] Bin Yang, et al., "Feasibility and Potential of Parabolic Trough Solar Thermal Power Plants in Tibet of China," APPEEC 2010, Asia-Pacific Power and Energy Engineering Conference, pp. 1-4, 2010.

[19] N. Kamal Raja, M. Shahid Khalil, S. Athar Masood, M. Shaheen, "Design and manufacturing of parabolic trough solar collector system for a developing country Pakistan," J. of American Science, vol. 7, no. 1, pp. 365-372, 2011.

[20] Lovegrove, Keith \& Stein, W (editors), "Concentrating Solar Power Technology: Principles, Developments and Applications," chapter eight by L. L. Vant-Hull, Woodhead publishing Ltd, 2012.

[21] Oloketuyi. S. Idowu, Oyewola M. Olarenwaju \& Odesola I. Ifedayo, "Determination of optimum tilt angles for solar collectors in low-latitude tropical region," International Journal of Energy and Environmental Engineering. Springer, vol. 4, no. 29, pp. 1-10, 2013.

[22] M. Masters, Gilbert, "Renewable and Efficient Electric Power Systems," A John Wiley \& Sons INC., publication, 2005.

[23] System Advisor Model (SAM), National Renewable Energy Laboratory (NREL). [Online]. Available: http://www.nrel.gov/analysis/sam.

[24] Wang Fuqiang, Cheng Ziming, Tan Jianyu, Yuan Yuan, Shuai Yong \& Liu Linhua, "Progress in concentrated solar power technology with parabolic trough collector system: A comprehensive review," Renewable and Sustainable Energy Reviews Elsevier, vol. 79, pp. 1314-1328, 2017.

[25] System Advisor Model (SAM)-Concentrating Solar Power Systems, manual, National Renewable Energy Laboratory (NREL), Version 12.2, 2011.

\section{BIOGRAPHIES OF AUTHORS}

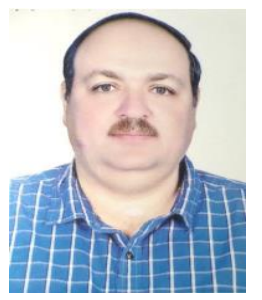

Riyadh T. Thahab, obtained his B.Sc in Electrical Enginnering from the University of Babylon in 1998. He was admitted to the graduate program in the University of Technology in Baghdad where he graduated with an M.Sc degree in electric power systems. He joined the Doctoral program at the college of Engineering and A pplied Sciences, Western Michigan University, USA, in 2012 and graduted in December 2017.

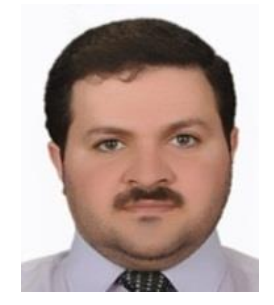

Ahmed Toman Thahab received his B.Sc in Electrical Enginnering from the University of Babylon in 2006. He was enrolled in the Graduate school of the same universty. He received his M.sc degree in the Communication and Electronic Engineering in 2011. 